\title{
Using the Think-Aloud Technique for Determining Different Reading Strategies Used by Iranian EFL Learners
}

\author{
Ladan Bakhshalinezhad \\ Department of English, Islamic Azad University, Urmia, Iran \\ Farahnaz Reymani Nikou (Corresponding author) \\ Department of English, Islamic Azad University, Urmia, Iran \\ E-mail: ni.kou@hotmail.com \\ Alireza Bonyadi \\ Department of English, Islamic Azad University, Urmia, Iran
}

Doi:10.7575/aiac.alls.v.6n.3p.15

Received: 02/01/2014

URL: http://dx.doi.org/10.7575/aiac.alls.v.6n.3p.15

Accepted: 05/03/2015

\begin{abstract}
This study explored the reading strategies used by advanced and intermediate Persian EFL learners in both English and Persian reading comprehension texts. Based on the aims of the study reading comprehension texts were administered to the learners and their reading strategies in both English and Persian reading comprehension texts were examined through the think-aloud method. The findings showed that while the advanced EFL learners employed all the strategies (which were included in the strategy table of the study) in their English texts, the intermediate learners used only some of them and also used their strategies with different frequencies in comparison with the advanced learners. Therefore, the findings supported the view that the use of the reading strategies may be related to the learners' proficiency level. The findings also supported the idea that reading strategies can be transferred from one language to another based on the learners' proficiency level.
\end{abstract}

Keywords: learning strategies, reading strategies, think aloud protocols, threshold level, transferability

\section{Introduction}

Second language researchers have mostly claimed that reading is one of the most significant language skills in language classrooms (Grabe \& Stoller, 2002). Reading in the first or the second language necessitates the elicitation of information from a piece of text, and its integration with background information (Anderson, 1991). According to Grabe and Stoller (2002) reading in a second language is a laborious task for second language learners since it requires the management of a large number of cognitive processes simultaneously.

The investigation of reading strategies began in 1970s, and many researchers tried to determine whether these strategies were consciously used by successful learners. According to Oxford (1990) reading strategies are a category of learning strategies. As she further argues learning strategies are certain strategies employed by the learners to make their learning process more manageable, and more practical. The results of many studies have revealed that the use of reading strategies is very effective for improving the reading ability of foreign language learners (Block, 1986).

Second language researchers have been concerned with the use of reading strategies in both the first and the second language of learners (Grabe \& Stoller, 2002). According to Cummins (1979) second language learners should achieve a certain level of proficiency in the second language to be able to transfer their reading ability from the first language to the second language. This hypothesis is referred to as the Linguistic Threshold Hypothesis. However, as Hudson (1982) argues the transfer of first language reading ability may be possible without any need for second language proficiency. According to him this hypothesis is referred to as the Linguistic Interdependence Hypothesis.

According to Oster (2001) think-aloud protocols are considered to be one of the important tools for investigating the reading strategies of language learners since their use enables the researchers to deal with strategies used during theprocess of reading. A review of the literature reveals that few studies have investigated the reading strategies of language learners in foreign language contexts. Based on this need for research in this area, the present study by comparing the different strategies used by advanced and intermediate Iranian EFL learners tries to give a clear understanding of these strategies in foreign language contexts, and also tries to determine the possibility of the transferability of reading strategies between the EFL learners' first language and second language. In order to achieve these goals the study tries to answer the following questions:

1. Which reading strategies are elicited from the advanced and intermediate EFL learners through think-aloud in English and Persian reading comprehension texts? 
2. Is there any difference between the strategies elicited from the advanced and intermediate learners through thinkaloud in English reading comprehension texts?

3. Is there any difference between the strategies elicited from the advanced and intermediate learners through thinkaloud in Persian reading comprehension texts?

4. Is there a threshold level for transferring reading strategies from Persian to English by Iranian EFL learners?

\section{Review of the Related Literature}

\subsection{The Importance of Reading}

Second language researchers have provided different definitions for reading. As Thorndike $(1917$, p. 425) stated "reading is a very elaborative procedure". According to him during the process of reading "the mind must select, repress, soften, emphasize, correlate and organize all under the influence of the right mental set or purpose or demand" (Thorndike, 1917, p. 431). According to Goodman (1967) reading is the most important skill in enabling the learners to expand their knowledge of the second language. As he further argues reading is the most important skill in the development of the human brain, and most of the cognitive procedures are improved by this skill. As he concludes this skill should be the main focus in second language classrooms.

\subsection{Language Learning Strategies}

According to Oxford (1990), the great interest in language learning strategies stems from the results of many empirical interlanguage studies which have revealed that these strategies are very important in the development of the learners' communicative competence. Various definitions have been proposed for language learning strategies. Some of these definitions focus on the meta-cognitive nature of these strategies, for example Fox and Matthews (1991, p. 56) stated that these strategies are "concerned with how learners use their brains consciously and purposefully to handle their learning and make it more effective". On the other hand some definitions focus on the communicative nature of these strategies such as the definition provided by Tarone (1980, p. 95 ) in which these strategies are defined as the actions taken by language learners to develop "linguistic and sociolinguistic competence in the target language -- to incorporate these into one's interlanguage competence" Finally some definitions have focused on the cognitive nature of these strategies, for example Mayer (1988, p. 11) stated that language learning strategies are "behaviors of a learner that are intended to influence how the learner processes information".

\subsection{Reading Strategies}

Block (1986) defines reading strategies as the tactics which are used by readers to facilitate their interaction with the information involved in the text. As the results of many studies have revealed, for a successful reading, readers need to acquire a variety of meta-cognitive reading strategies in an efficient way (Anderson, 2003).

Similar to learning strategies, the definitions of reading strategies by second language researchers focus on different characteristics of these strategies. Some definitions emphasize the goal-oriented nature of these strategies, for example according to Cook and Mayer (1983, p. 90) reading strategies are actions which a learner "engages in at the time of reading and that it is related to some goals". Other definitions focus on the cognitive nature of these strategies such as the definition by Barnett (1989) in which reading strategies are defined as the cognitive processes that are undertaken by the readers to comprehend a text. Finally some definitions deal with the situation dependency of these strategies, for example Cohen (1998) argues that reading strategies are the procedures which the readers consciously select based on the requirements of the different reading assignments.

\subsection{Think-aloud Method}

According to Oster (2001, p. 54) think-aloud is a method in which "students verbalize their thoughts as they read and thus bring into the open the strategies they are using to understand a text". As he further argues this method is used to gather data about the cognitive processes that are not observable in a variety of tasks such as mathematical computation or reading. As he concludes this method is best for clarifying the steps that are taken in the process of performing a cognitive task.

\section{Method}

\subsection{Participants}

Thirty EFL learners at advanced and intermediate proficiency levels from Urmia branch of Academic Center for Education, Culture and Research (ACECR) took part in this study. All of the participants, whose ages ranged between 17 and 24 were female and had 3 to 4 years of English study at ACECR. At the time of the study (Summer 2013) the learners were selected for the study and divided to intermediate and advanced proficiency levels with fifteen learners in each proficiency level on the basis of their course books in the language center, and also the results of a placement test which homogenized the participants in each proficiency level.

\subsection{Materials}

The following instruments were used in this study:

\subsubsection{Placement Test}

In order to guarantee the validity of the results of the study it was essential to make sure that participants were placed in appropriate levels on the basis of their language proficiency. For this reason Objective Placement Test, from New 
Interchange Passages Placement and Evaluation Package (Lesley, Hansen, \&Zukowski/Faust, 2003) was used in this study.

\subsubsection{Reading Comprehension Texts}

The researcher of this study used ten English and ten Persian reading texts for each proficiency level. All of the English and Persian texts in each proficiency level were suitable for that level and were different from the English and Persian texts in the other proficiency level. All of the English reading comprehension texts used in the present studywere selected from English through Reading (Sevgi Ondes, 2004) which is a book that provides reading comprehension texts for different proficiency levels. All of the texts were nearly 150 words in length and were given to students in advanced and intermediate groups to determine their reading strategies. All of the Persian reading comprehension texts of the study were selected from Farsi Omumi: Darsnameye Daneshgahi (Fotouhi\&Abbasi, 2012) which includes texts that are compatible with the age and the level of comprehension of the advanced and intermediate level students.

\subsubsection{Meta-cognitive Reading Strategy Framework}

Based on the objectives of the study a reading strategy framework developed by Ghuma (2011, pp. 55-56) was used in this study for determining the strategies used by the advanced and intermediate EFL learners in English and Persian reading texts. This framework consists of twenty-four strategy categories. As Ghuma (2011) claims this framework is a combination of different classifications of reading strategies by different researchers, and as a result covers almost all of the meta-cognitive reading strategies. This framework is provided in Table 1 below.

Table 1. Meta-cognitive reading strategy framework (Ghuma, 2011, pp. 55-56)

\begin{tabular}{|c|c|}
\hline Strategy & Definition \\
\hline Association & $\begin{array}{l}\text { is to link part or all of the text to prior knowledge, experience, } \\
\text { environment, or other texts. This relationship is established either before, } \\
\text { while, or after reading. }\end{array}$ \\
\hline Clarifying & is to explain or elaborate an idea or linguistic body presented in the text. \\
\hline $\begin{array}{l}\text { Defining text type/ } \\
\text { structure }\end{array}$ & $\begin{array}{l}\text { is to be able to distinguish the text type on the basis of its own } \\
\text { characteristics. }\end{array}$ \\
\hline $\begin{array}{l}\text { Drawing } \\
\text { conclusions }\end{array}$ & $\begin{array}{l}\text { is to be able to highlight the message/s targeted by the writer, and } \\
\text { learning something new. }\end{array}$ \\
\hline Evaluation & is to express appreciation or an opinion of the text or any of its parts \\
\hline Guessing meaning & $\begin{array}{l}\text { is to get the meaning of unknown words, phrases, or sentences through } \\
\text { linguistic items such as titles, structures, etc or paralinguistic hints such as } \\
\text { pictures. }\end{array}$ \\
\hline $\begin{array}{l}\text { Identifying the } \\
\text { idea }\end{array}$ & $\begin{array}{l}\text { is to find out the message introduced in the text or in any of its parts by referring } \\
\text { back to linguistic items. }\end{array}$ \\
\hline Inference & $\begin{array}{l}\text { is to elicit the implications of a certain linguistic body based on prior } \\
\text { knowledge or experience. }\end{array}$ \\
\hline Morphology & $\begin{array}{l}\text { is to show knowledge of the morphological characteristics of certain words } \\
\text { that may assist comprehension. }\end{array}$ \\
\hline Prediction & $\begin{array}{l}\text { is to anticipate what is coming in the text based on what is grasped } \\
\text { through skimming, titles, or any other means. }\end{array}$ \\
\hline Recalling & is to reproduce a similar version of the text without referring back to the text. \\
\hline Linking items & is to relate a referent and an anaphoric expression to each other. \\
\hline Re-reading & is to read again to either test or emphasize comprehension. \\
\hline Responding & $\begin{array}{l}\text { is to express feeling or reaction toward the content of the text or toward any of } \\
\text { its parts. }\end{array}$ \\
\hline Restating & is to reproduce a similar version of the text by using reader's own words. \\
\hline Scanning & is to define specific information that is explicitly mentioned in the text. \\
\hline Skimming & is to seek general information that is clearly stated in the text. \\
\hline Summarizing & is to produce a short and condensed version of the text. \\
\hline Syntax & $\begin{array}{l}\text { is to identify the syntactic relations between the words, phrases, and } \\
\text { clauses. }\end{array}$ \\
\hline Thesis statement & is to define the linguistic body that conveys the message of the text. \\
\hline Topic sentence & is to define the linguistic body that conveys the message of the paragraph \\
\hline Title awareness & $\begin{array}{l}\text { is to suggest or match a title to a text. Reader's decision is based on } \\
\text { linguistic and/ or non-linguistic clues that is explicitly presented in the text. }\end{array}$ \\
\hline Language usage & $\begin{array}{l}\text { is to link a certain word, phrase or syntactic structure to a situation, } \\
\text { function and/ meaning. }\end{array}$ \\
\hline Using Dictionary & is to consult a dictionary to find out the meaning of a word or a phrase. \\
\hline
\end{tabular}




\subsection{Design}

The main aim of the present study was the determination of the steps that EFL learners take in the process of their reading. The focus of the study was the revelation of the meta-cognitive strategies which are employed in performing reading tasks. Therefore because data were elicited from the advanced and intermediate EFL learners in English and Persian reading texts and there was no treatment, the design of this study was descriptive.

\subsection{Procedures}

The present study tried to follow the principle of random sampling to guarantee the validity of its results. Therefore first a placement test was administered to place the learners in appropriate levels. Then based on the results of the placement test $30 \mathrm{EFL}$ learners were assigned to intermediate and advanced levels with 15 learners in the intermediate and 15 learners in the advanced level. Before the administration of the treatment of the study, the reading texts for both of the proficiency levels were piloted with ten EFL learners at each proficiency level to detect any problems. At the beginning of the main phase of the study, one sample of English reading comprehension texts and one sample of Persian reading comprehension texts were given to each learner in both of the proficiency levels as a practice task to prepare them for the administration of the reading comprehension texts. The researcher herself also showed the participants how the students were to read and think aloud at the same time by performing a think aloud with a sample text for the students, both in English and in Persian texts in which she read out a sample text and verbalized the strategies she was using while reading the text. Thereafter, each participant read the reading comprehension texts and verbalized her strategies according to the think-aloud technique in separate sessions for English and Persian texts.

While the learners were using the think-aloud technique everything was recorded by an MP4 recorder. Next the researcher transcribed and analyzed the recordings to determine the strategies used by the advanced and intermediate learners in both English and Persian reading comprehension texts. Finally the researcher quantified the different strategies used by the advanced and intermediate learners in English and Persian texts according to the strategy table of the study.

\section{Findings}

In this study, in order to analyze the data the researcher listened to the recordings of the students' self-reports and transcribed them, then with the help of the strategy table of the study, she was able to tally the strategies for the advanced and intermediate EFL learners and to quantify them. In what follows, the research questions of the study are answered based on the results of data analysis.

Research question 1:Which reading strategies are elicited from advanced and intermediate Iranian EFL learners through think-aloud in English and Persian reading comprehension texts?

The analysis of the advanced EFL learners' think-aloud recordings revealed that these learners almost used all of the strategies included in the strategy table of the study in English reading comprehension texts. The frequencies of the strategies which were used by this group in English texts are visually provided in Figure 1 below.

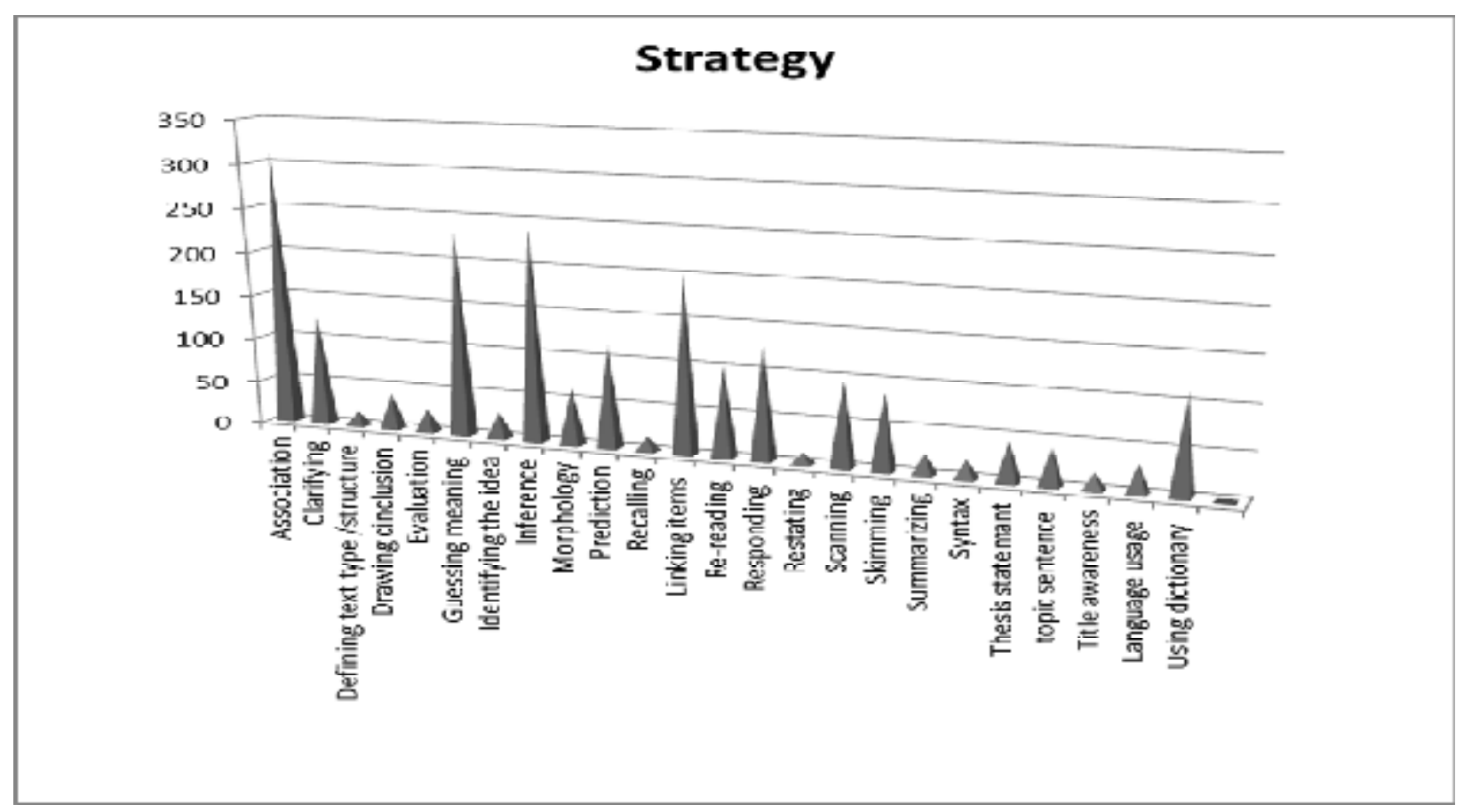

Figure 1. Frequencies of the Strategy Categories Used by Advanced EFL Learners in English Reading Comprehension Texts

The analysis of the data for the intermediate EFL learners revealed that these learners like the advanced EFL learners employed most of the strategies included in the strategy table of the study in English texts, but with different frequencies. However, there were some strategies that intermediate EFL learners did not use in their English reading 
texts. These strategies which were only used by the advanced EFL learners included: defining text type structure, evaluation, recalling, restating, syntax, title awareness and summarizing. The actual frequencies of the strategies employed by the intermediate EFL learners in English reading comprehension texts are provided in Figure 2 below.

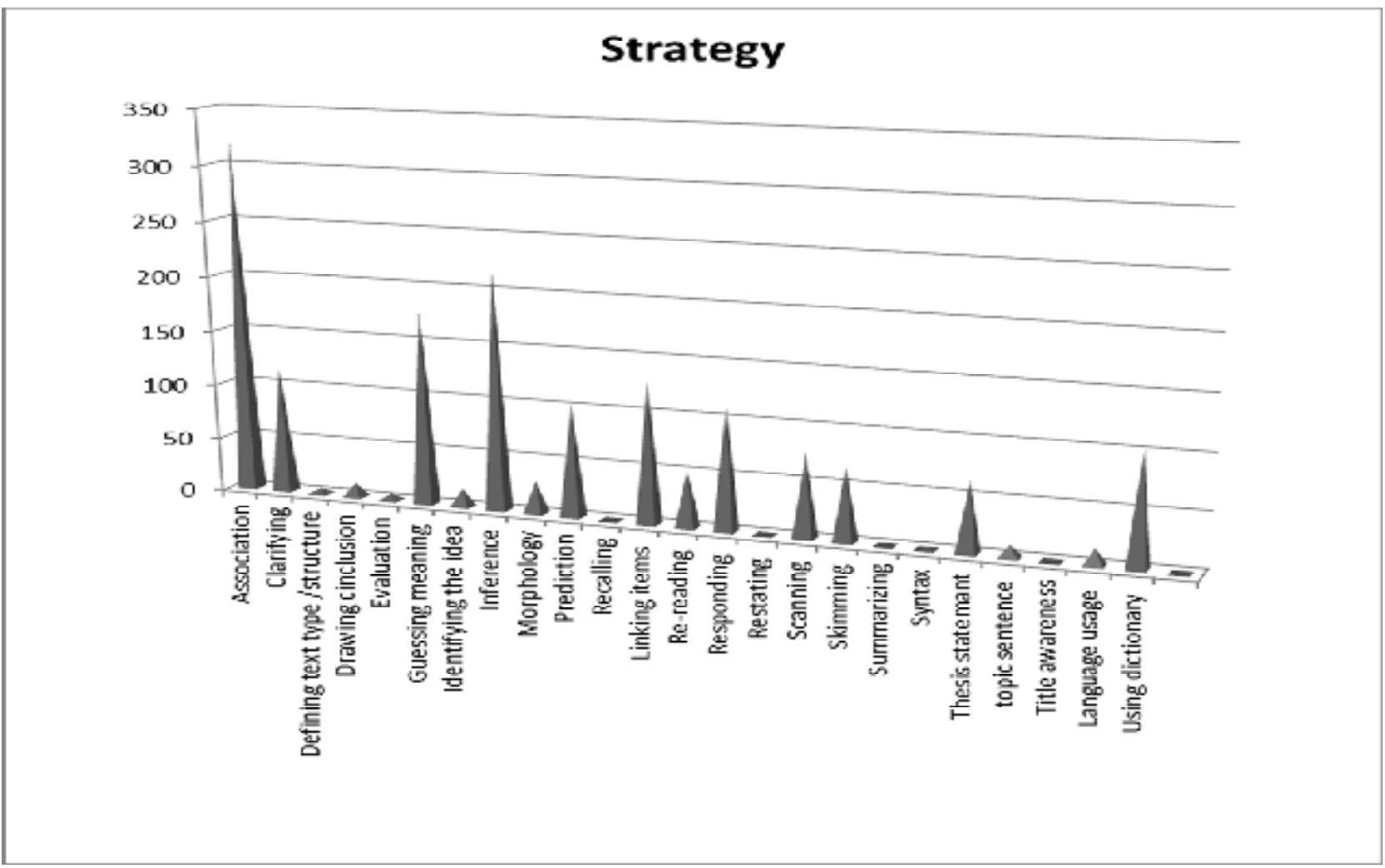

Figure 2. Frequencies of the Strategy Categories Used by Intermediate EFL Learners in English Reading Comprehension Texts

The analysis of the data for the advanced EFL learners regarding their strategy use in Persian reading comprehension texts revealed that these students employed all the strategies which were included in the strategy table of the study. The actual frequencies of the strategies used by this group in Persian reading comprehension texts are provided in Figure 3 below.

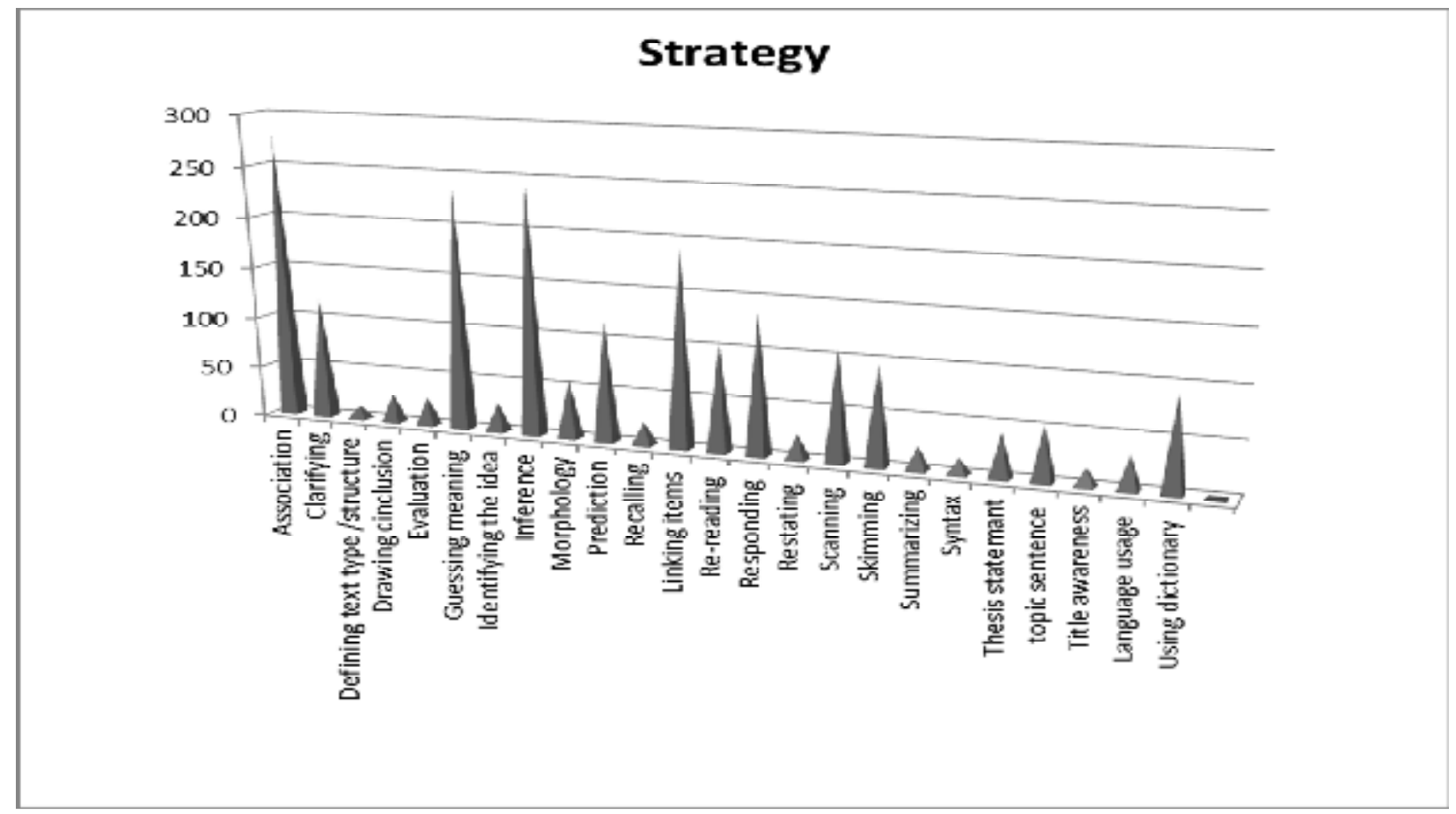

Figure 3. Frequencies of the Strategy Categories Used by Advanced EFL Learners in Persian Reading Comprehension Texts

The analysis of the data for the intermediate EFL group regarding their strategy use in Persian reading comprehension texts revealed that these learners employed similar strategies to advanced EFL learners in Persian reading 
comprehension texts, and also they used them with similar frequencies to the advanced group. The actual frequencies of the strategies of these learners in Persian reading comprehension texts are provided in Figure 4 below.

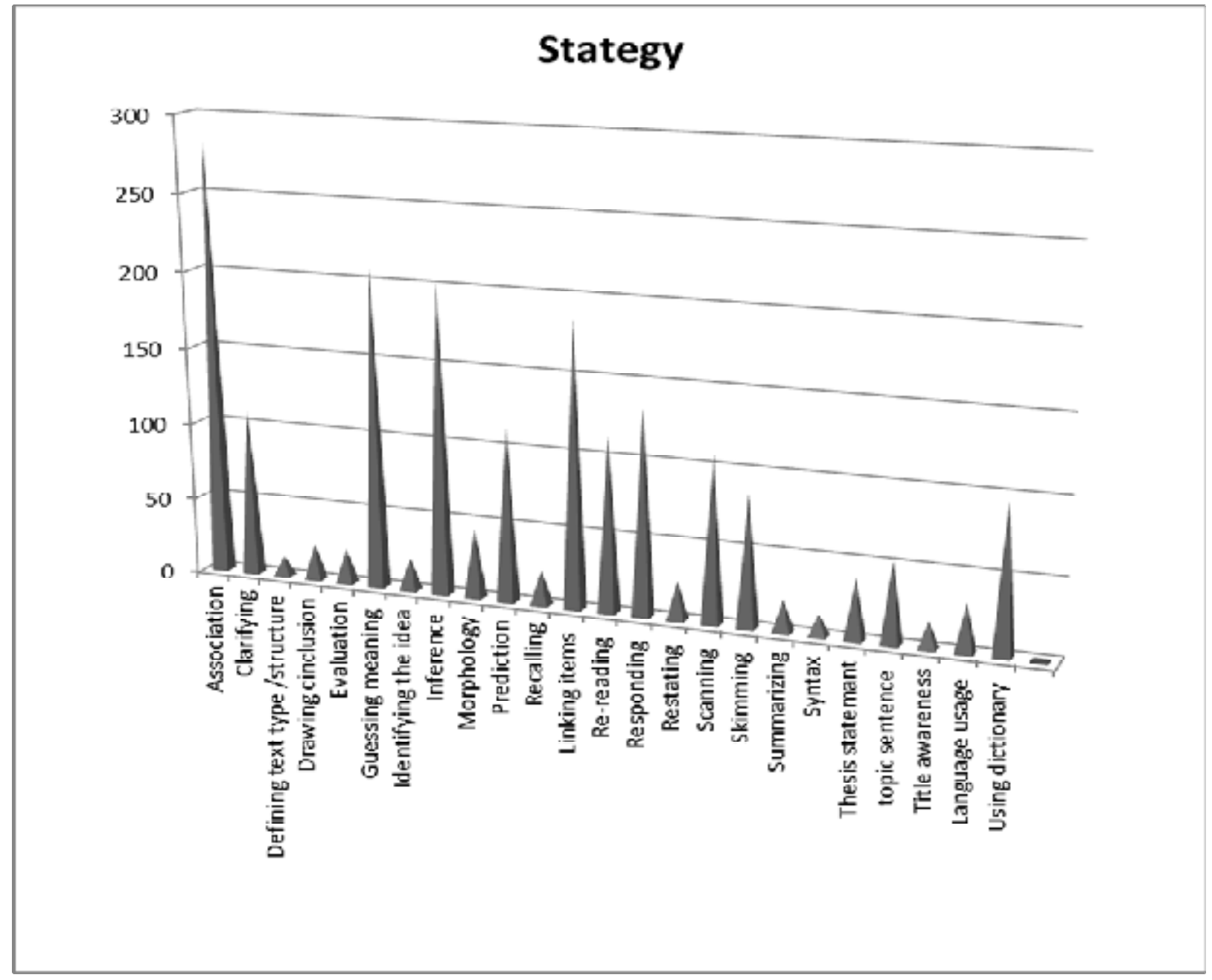

Figure 4. Frequencies of the Strategy Categories Used by Intermediate EFL Learners in Persian Reading Comprehension Texts

Research question 2: Is there any difference between the strategies elicited from the advanced and intermediate Iranian EFL learners through think-aloud in English reading comprehension texts?

The analysis of the data for advanced and intermediate EFL learners regarding their strategy use in English reading comprehension texts revealed that the advanced EFL learners employed all of the strategies which were included in the strategy table of the study (see Figure 1). However the intermediate EFL learners did not use all of the strategies included in the strategy table of the study (see Figure 2). Therefore it is obvious that some strategies were used only by the advanced EFL learners in English reading comprehension texts. These strategies included: defining text type structure, evaluation, recalling, restating, syntax, title awareness, and summarizing.

Therefore, based on the results of data analysis for the advanced and intermediate EFL learners regarding their strategy use in English reading comprehension texts, it can be argued that advanced EFL learners employed more strategies in English reading comprehension texts and also employed them more frequently in comparison with the intermediate learners; therefore their strategy use differed from intermediate EFL learners.

Research question 3: Is there any difference between the strategies elicited from the advanced and intermediate Iranian EFL learners through think-aloud in Persian reading comprehension texts?

The results of data analysis for the advanced and intermediate EFL learners regarding their strategy use in Persian reading comprehension texts revealed that both of these groups employed all of the strategies included in the strategy table of the study and their strategy categories had similar frequencies in Persian reading comprehension texts (see Figure 3 \& Figure 4). Therefore, based on the results of data analysis for the advanced and intermediate EFL learners in Persian reading comprehension texts, it can be argued that their strategy use was similar.

Research question 4: Is there a threshold level for transferring reading strategies from Persian to English by Iranian EFL learners?

The analysis of the data for advanced and intermediate EFL learners regarding their strategy use in Persian reading comprehension texts revealed that both of these groups employed similar strategies (see Figure $3 \&$ Figure 4). However data analysis also revealed that advanced and intermediate EFL learners employed different strategies in English 
reading comprehension texts with different frequencies (see Figure 1\& Figure 2). Therefore, it is obvious that some strategies including: defining text type structure, evaluation, recalling, restating, syntax, title awareness, and summarizing were used only by the advanced EFL group in English reading comprehension texts. These results seem to show that only the advanced group was able to transfer these strategies from Persian texts to English texts and used them in English reading comprehension texts, while the intermediate group was not able to transfer them and as a result could not employ them in English reading comprehension texts. Therefore, based on the results of the data analysis, it can be argued that there may be a threshold level for strategy transfer from Persian to English for Iranian EFL learners.

\section{Discussion}

Ellis (2008) after an examination of the results of many empirical studies of strategy use by language learners concluded that, the strategies that the learners select to use, reflect their general proficiency level, and meta-cognitive strategies are mostly employed by advanced learners. He further noted that the learners which are at higher proficiency levels employ more learning strategies, and also use them more frequently in comparison with learners who are less proficient. Clapham (1993) argued that strategy use in second language reading tasks is greatly dependent on the learners' proficiency level, and more proficient learners have a better comprehension of reading texts as a result of the efficient and more appropriate strategies that they use. In this study, the results of data analysis regarding the first and the second research questions supported Ellis' (2008) conclusion because they revealed that advanced learners employed a number of strategies in English reading comprehension texts which were not used by the intermediate EFL group. Therefore as Clapham (1993) argued, it seems that the advanced learners' stage of development and higher proficiency in English had a beneficial effect on their strategy use and enabled them to use more meta-cognitive strategies with a higher frequency in comparison with the intermediate EFL learners.

Regarding the third research question, the results of the data analysis revealed that both the advanced and intermediate EFL learners employed all of the strategies included in the strategy table of the study similarly in Persian reading comprehension texts with similar frequencies. These results were expected because the participants, regarding their ages, did not greatly differ from each other and roughly had equal years of education in Persian language. This seems to be the reason behind their similarity regarding their strategy use in Persian reading comprehension texts. Since all of them were equally proficient in this language, they were able to use all of the meta-cognitive strategies included in the table of the strategy of the study.

Cummins (1979) proposed the Linguistic Threshold Hypothesis according to which language learners should reach a certain degree of proficiency in the second language in order to transfer their reading ability from their mother tongue to the second language. In this study, according to the results of the data analysis for the advanced and intermediate EFL learners in English and Persian reading comprehension texts, only advanced EFL learners were able to transfer a number of strategies from Persian to English reading comprehension texts. It seems that as a result of their higher proficiency, advanced learnerswere able to transfer some strategies from Persian to English reading comprehension texts while the intermediate learners were not able to transfer these strategies and did not use them in English reading texts. Therefore, it can be argued that the results of the present study seem to support the Linguistic Threshold Hypothesis.

\section{Conclusion}

The present study tried to determine the reading strategy use of Iranian EFL learners through the think-aloud research method. The findings revealed that the advanced EFL learners used more meta-cognitive strategies in English reading comprehension texts and also used them more frequently while the intermediate EFL learners were not able to use all the strategies employed by the advanced EFL learners. The results also revealed that only the advanced learners were able to transfer all of their reading strategies from Persian texts to English texts. Based on these findings it can be concluded that as Cummins (1979) argued, there may be a certain threshold level for language learners' proficiency in the second language that determines their ability to transfer their reading ability from their first language to their second language. However, more research studies are needed to clarify the reading strategy use of EFL learners, and to support the findings of this study.

The results of the study may have certain pedagogical implications for EFL classroom teachers and syllabus designers. Based on the findings, it seems that the intermediate EFL learners may benefit from some explicit and implicit instruction regarding L2 reading strategies in the EFL classrooms and EFL teachers should try to include the instruction of these reading strategies especially in the intermediate EFL classrooms since these reading strategies not only help EFL learners to improve their L2 knowledge but also help them increase their control over their existing linguistic resources. Furthermore, these reading strategies will help intermediate EFL learners to decrease the processing burden on their cognitive system by increasing their processing ability in their L2 reading tasks.

Finally, as the results revealed, it is advisable to develop materials including some parts for strategy training so as a way to increase learners' opportunity of learning these strategies, leading to a higher level of proficiency among EFL learners, and so, syllabus designers and material developers are recommended to adopt new approaches for developing course materials which view language learning based on classroom research findings, and develop and include materials with parts for strategy training in the course books for EFL learners, especially, in the intermediate level of proficiency. 


\section{References}

Anderson, N. J. (1991). Individual differences in strategy use in second language reading and testing.Modern Language Journal, 75, 460-472.

Anderson, N. J. (2003). Scrolling, clicking and reading English: Online reading strategies in a second/foreign language. The Reading Matrix: An International Online Journal, 3(3), 1-33.

Barnett, M.A. (1989). More than meets the eye. Foreign language reading: Theory and practice. EnglewoodsClifts, N. Jersey: Prentice-Hall.

Block, E. L. (1986). The comprehension strategies of second language readers.TESOLQuarterly, 20(3), 463-493.

Clapham, C. (1993). Is ESP testing justified? In D, Doughlas,\& C, Chapelle (Eds), A new decade of language testing research: Selected papers from the 1990 language testing research colloquium(pp. 257-27). Oxford: Oxford University Press.

Cohen, A.D. (1998). Strategies in learning and using a second language. London: Longman.

Cook, L.K. \& Mayer, R.E. (1983). Reading strategies training for meaningful learning from prose.In M. Pressley and J.R Levin (Eds.).Cognitive strategy research. Springler-Verlag: New York.

Cummins, J. (1979).Linguistic interdependence and the educational development ofbilingual children, Review of Educational Research, 49(2), 222-251.

Ellis, R. (2008). The study of second language acquisition ( $\left.2^{\text {nd }} \mathrm{ed}\right)$. Oxford, England Oxford University Press.

Fotuhi, M. \&Abbasi, H.(2012).Farsi Omumi: DarsnameyeDaneshgahi. Tehran: MaharatPublication.

Fox, J. \& Matthews, C. (1991).Learner strategies and learner needs in the design of CALL help systems, proceedings of EUROCALL. London:Helsinki.

Ghuma, M.A. (2011). The transferability of reading strategies between L1 (Arabic) and L2 (English) (doctoral dissertation).University of Durham: England.

Goodman, K. (1967). Reading: A psycholinguistic guess game. Journal of the Reading Specialist, 4, 126-135.

Grabe, W. \&Stoller, F. L. (2002) Teaching and researching reading, London: PearsonEducation.

Hudson, T. (1982).The effects of induced schemata on the short circuit in L2 reading: Non-decoding factors in L2 reading performance, Language Learning, 32 (1), 1-31.

Lesly, T., Hansen, Ch., \&Zukowski/Faust, J. (2003).New interchange passages placement andevaluation package. New York, NY: Cambridge University Press.

Mayer, R. (1988). Learning strategies: An overview. In C. Weinstein, E. Goetz,\& P. Alexander (Eds.), Learning and Study Strategies: Issues in Assessment, Instruction, and Evaluation (pp. 11-22). New York: Academic Press.

Oster, L. (2001). Using thing-aloud for reading instruction. The Reading Teacher, 55(1), 64-69.

Oxford, R. L. (1990). Language learning strategies: What every teacher should know. Boston: Heinle and Heinle Publishers.

SevgiOndes, N. (2004). English through reading. Istanbul: YapimTanitimYayincilik LTD.

Tarone, E. (1980).Communication strategies, foreigner talk, and repair in interlanguage. Language learning, 30, 41731.

Thorndike, E.L. (1917). Reading as reasoning.Journal of Educational Psychology, 8, $323-332$. 